\title{
UPAYA PENINGKATKAN PENGETAHUAN SADARI KELUARGA PENDERITA KANKER PAYUDARA DENGAN PENDEKATAN HEALTH BELIEFE MODEL
}

\author{
Yuniastini*, Ratna Dewi*, Arif Yulinda* \\ *Jurusan Keperawatan Poltekkes Tanjungkarang \\ E-mail: yunitinimm@yahoo.co.id
}

\begin{abstract}
Kanker payudara banyak terjadi pada wanita. Di Lampung, pada tahun 2014, jumlah penderita kanker payudara adalah yang tertinggi dan sebagian besar datang pada stadium lanjut. Stadium kanker payudara saat terdiagnosis berhubungan dengan survival rate yang ditimbulkan oleh kanker tersebut. Semakin dini stadium kanker terdiagnosis maka semakin banyak penderita dengan daya tahan hidup selama lima tahun (five-year relative survival rate). Tujuan penelitian ini meningkatkan pengetahuan tentang kanker payudara dan sadari keluarga penderita kanker payudara dengan pendekatan Health Beliefe Model (HBM). Penelitian dirancang dengan pendekatan One Group Pretest-Posttest. Sampel penelitian adalah sebagian dari keluarga pasien kanker payudara dengan kriteria: merupakan keluarga pasien kanker payudara dari satu garis keturunan, berjenis kelamin perempuan, berusia $\geq 20$ tahun, dalam kondisi sehat dan bersedia berpartisipasi dalam penelitian berjumlah 30 orang. Media yang digunakan video, dirancang dengan pendekatan HBM, yakni dengan memasukkan konstruksi dari HBM yakni perceived seriousness, perceived susceptibility, perceive benefits, perceived barriers, cues to action, motivating factors, selfefficacy. Pengetahuan yang ditayangkan dalam media meliputi pengertian, tanda dan gejala kanker payudara, faktor resiko kanker payudara, manfaat sadari dan teknik sadari. Analisis yang digunakan Wilcoxon Signed Ranks Test. Hasil penelitian diperoleh adanya perbedaan antara pengetahuan keluarga penderita kanker payudara sebelum dan sesudah diberikan perlakuan dengan pendekatan HBM $(p=0,000$ ; positive ranks 22). Kesimpulan, pendekatan HBM secara signifikan dapat meningkatkan pengetahuan keluarga penderita kanker payudara dan disarankan untuk diterapkan.
\end{abstract}

Kata Kunci: Health Beliefe Model, Pengetahuan, Video

\section{LATAR BELAKANG}

Kanker payudara merupakan penyakit keganasan yang berasal dari sel kelenjar, saluran kelenjar dan jaringan penunjang payudara, namun tidak termasuk kulit payudara (Menteri Kesehatan, 2015). Biasanya tidak ada gejala saat tumor kecil. Bila kanker payudara telah tumbuh dengan ukuran yang bisa dirasakan, tanda fisik yang paling umum adalah benjolan tanpa rasa sakit. Terkadang kanker payudara bisa menyebar ke kelenjar getah bening ketiak dan menyebabkan benjolan atau pembengkakan, bahkan sebelum tumor payudara asli cukup besar untuk bisa dirasakan. Tanda dan gejala yang kurang umum adalah nyeri payudara; perubahan terus-menerus pada payudara, seperti pembengkakan, penebalan, atau kemerahan pada kulit payudara; dan kelainan puting susu seperti tanpa menyusui payudara mengeluarkan darah atau cairan yang lain, erosi, inversi, atau nyeri tekan (American Cancer Society, 2015).

Di Indonesia pada tahun 2013, prevalensi penyakit kanker pada penduduk semua umur, sebesar 1,4\%o atau diperkirakan sekitar 347.792 orang, sementara prevalensi penyakit kanker payudara sebanyak $0,5 \%$ dengan perkiraan jumlah absolut sebanyak 61.682 . Prevalensi kanker payudara tersebut di atas adalah yang tertinggi kedua setelah kanker serviks yakni 0,8\%o (Kemenkes,2015).

Di Rumah Sakit Kanker Dharmais Jakarta, setiap tahun kasus kanker baru payudara mengalami peningkatan. Tahun 2010 sampai 2013 adalah : $711 ; 769 ; 802$ ; 819. Sementara jumlah kematian 93 ; $120 ; 130 ; 217$. Jumlah kasus baru kanker payudara dan kematian ini merupakan 
kasus tertinggi di rumah sakit tersebut (Kemenkes RI, 2015).

Di Lampung pada tahun 2013, angka kejadian kanker payudara pada perempuan menurut provinsi, sebanyak 0,3\% dengan perkiraan jumlah absolut sebanyak1.148 (Kemenkes RI ,2015). Pada tahun 2014, berdasarkan laporan yang masuk dari 25 rumah sakit yang ada di Provinsi Lampung, jumlah penderita kanker yang berkunjung dan dirawat selama tahun 2014 adalah 2.119 untuk kanker payudara, lebih banyak dari kanker leher rahim yang berjumlah 383 pasien (Ficardo, 2015). Pada tahun 2014, di Rumah Sakit dr.H.Abdul Moeloek (RSAM) Provinsi Lampung jumlah penderita kanker payudara sebanyak 392 orang (RSAM, 2017).

Stadium kanker payudara saat terdiagnosa berhubungan dengan survival rate yang ditimbulkan oleh kanker tersebut. Semakin dini stadium kanker terdiagnosa maka semakin banyak penderita dengan umur ketahanan hidup selama lima tahun (five-year relative survival rate). Di Amerika, five-year relative survival rate pada penderita kanker yang terlokalisir (localized disease) adalah 99\%, pada penderita regional disease adalah $84 \%$ dan pada penderita kanker yang telah menyebar jauh (distantstage disease) adalah 24\%. Survival rate berhubungan juga dengan besarnya ukuran tumor saat terdiagnosa. Umur five-year relative survival rate adalah $95 \%$ pada penderita dengan ukuran tumor $<2 \mathrm{~cm}$; $83 \%$ pada penderita dengan ukuran tumor $2,1 \mathrm{~cm}-5 \mathrm{~cm}$; dan $65 \%$ penderita dengan ukuran tumor $>5 \mathrm{~cm}$ (American Cancer Society ,2013). Sementara di India, fiveyear relative survival rate adalah $85 \%$ pada kasus yang terdiagnosa dini, 56\% pada kasus yang terdiagnosa lambat (Shrivastava Saurabh RamBihariLai, dkk, 2013).

Deteksi dini dari kanker payudara merupakan sesuatu yang sangat penting dalam meningkatkan survival rate dan quality of life. Program deteksi dini yang ada adalah sadari (pemeriksaan payudara sendiri/ breast self-examination), sadanis (pemeriksaan klinik / Clinical Breast Examination) dan mamografi (mammography). Keunggulan dari sadari adalah dapat dilakukan sendiri dengan biaya murah.

Pada saat ini, walaupun wanita adalah faktor resiko yang sangat penting untuk kanker payudara, (Susan, 2010) dan sadari sangat mudah untuk dilakukan (Shalini, Varghese \& Nayak, 2011), namun masih banyak masyarakat yang belum sadar untuk melakukan sadari sebagai upaya melindungi dirinya dari bahaya kanker payudara. Hasil penelitian Alwan Nada A.S (2012) hanya 42,6\% dari 256 partisipan in Kirkuk University, Iraq yang melakukan sadari. Sementara hasil penelitian Zavare Mehrnoosh Akhtari, Muhamad Hanafiah Juni, Salmiah Md Said \& Irmi Zarina Ismail, (2013), 36,7\% mahasiswa S1 di Universitas Putra Malaysia melakukan sadari.

Ada beberapa faktor yang mempengaruhi kesadaran tentang kanker payudara masih rendah. Hasil penelitian Mitra Moodi, dkk (2011), menyebutkan pengetahuan, kepercayaan dan sikap tentang penyakit, merupakan faktor penting dalam melakukan atau tidak melakukan perilaku sadari. Shiryazdi Seyed Mostafa (2014) mengungkapkan, perilaku deteksi dini kanker payudara pada petugas kesehatan perempuan Iran berhubungan dengan komponen 'kepercayaan' yang meliputi dirasakan terhadap kerentanan, tingkat keparahan, manfaat, hambatan, dan self-efficacy.

Teori tentang kepercayaan dan prilaku kesehatan telah banyak berkembang. Salah satunya HBM (Health Belief Model). HBM merupakan teori perubahan prilaku kesehatan dan model psikologis dengan fokus pada persepsi dan kepercayaan individu terhadap suatu penyakit. Dalam konsep HBM, seorang individu akan melakukan tindakan yang berhubungan dengan kesehatan berdasarkan persepsi dan kepercayaannya (Priyoto, 2014). HBM dikembangkan sejak tahun 1950-an oleh Godfrey Hochbaum, psikolog sosial di Amerika Serikat. Pada awalnya, konsep HBM dipergunakan 
untuk menjelaskan faktor-faktor yang berhubungan dengan partisipasi masyarakat dalam program skrening tuberculosis (Steckler Allan, Kenneth R. McLeroy, Deborah Holtzman, 2010).

\section{METODE}

Penelitian dirancang dengan pendekatan One Group Pretest-Posttest, dengan sampel penelitian adalah sebagian dari keluarga pasien kanker payudara dengan kriteria: merupakan keluarga pasien kanker payudara dari satu garis keturunan, berjenis kelamin perempuan, berusia $\geq 20$ tahun, dalam kondisi sehat dan bersedia berpartisipasi dalam penelitian. Jumlah sampel dalam penelitian ini adalah 30 responden.

Media yang digunakan, dirancang dengan pendekatan HBM, yakni dengan memasukkan konstruksi dari HBM yakni perceived seriousness, perceived susceptibility, perceive benefits, perceived barriers, cues to action, motivating factors, self-efficacy. Pengetahuan yang ditayangkan adalah pengertian, tanda dan gejala kanker payudara, faktor resiko kanker payudara, manfaat sadari dan teknik sadari.

Langkah penelitian yang dilakukan adalah partisipan melakukan: mengisi identitas dirinya yang meliputi: dokumen kependudukan; status kesehatan; gaya hidup yang berhubungan dengan kanker payudara, mengisi kuesioner pretest pengetahuan berjumlah 30 soal, menonton video yang telah dirancang dengan pendekatan HBM dan mengisi kuesioner posttest pengetahuan berjumlah 30 soal. Data pretest dan post test selanjutnya dianalisis menggunkan Wilcoxon Signed Ranks Test.

\section{HASIL}

\section{Anlaisis Univariat}

Tabel 1: Karakteristik Demografi Keluarga Penderita Kanker Payudara

\begin{tabular}{llcc}
\hline \multicolumn{1}{c}{ Karakteristik } & $\mathrm{f}$ & $\%$ \\
\hline \multirow{4}{*}{ Usia } & $20-30$ tahun & 7 & 23 \\
\cline { 2 - 4 } & $31-40$ tahun & 9 & 30 \\
\cline { 2 - 4 } & $41-50$ tahun & 8 & 27 \\
\cline { 2 - 4 } & $51-60$ tahun & 5 & 17 \\
\cline { 2 - 4 } Pendidikan & SD & 5 & 16,7 \\
\cline { 2 - 4 } & SMP & 11 & 36,6 \\
\cline { 2 - 4 } & SMA & 9 & 30,0 \\
\cline { 2 - 4 } Pekerjaan & PT & 5 & 16,7 \\
\hline \multirow{2}{*}{ Pernikahan } & Tidak Bekerja & 23 & 76,7 \\
\cline { 2 - 4 } & Bekerja & 7 & 23,3 \\
\cline { 2 - 4 } & Belum Menikah & 3 & 10,0 \\
\cline { 2 - 4 } & Nikah & 25 & 83,3 \\
\hline
\end{tabular}

Tabel di atas menggambarkan karakteristik partisipan sangat beragam. Usia terbanyak dalam rentang 31- 40 tahun (30\%). Pendidikan terbanyak adalah pendidikan rendah yakni SD dan SMP $(53,3 \%)$. Pekerjaan terbanyak adalah ibu rumah tangga/tidak bekerja $(76,7 \%)$. Status pernikahan terbanyak adalah menikah $(83,3 \%)$.

Tabel 2: Faktor Resiko Keluarga Penderita Kanker Payudara

\begin{tabular}{|c|c|c|c|}
\hline \multicolumn{2}{|c|}{ Karakteristik } & $\mathrm{f}$ & $\%$ \\
\hline \multirow{3}{*}{ Status Gizi } & Kurus & 2 & 6,7 \\
\hline & Normal & 19 & 63,3 \\
\hline & Gemuk* & 9 & 30 \\
\hline \multirow{3}{*}{ Usia Menarche } & $<11$ thn* & 13 & 43,3 \\
\hline & $\geq 11$ thn & 11 & 36,7 \\
\hline & Lain-lain & 6 & 20 \\
\hline \multirow{2}{*}{$\begin{array}{l}\text { Usia Kehamilan } \\
\text { Pertama }\end{array}$} & $<31$ thn & 25 & 89 \\
\hline & $\geq 31$ thn* & 3 & 11 \\
\hline
\end{tabular}

Pada tabel di atas tergambar, faktor resiko kanker payudara pada keluarga penderita kanker payudara: gemuk $(30 \%)$; usia menarche kurang dari 11 tahun $(43,3 \%)$; mengalami menopouse pada 
usia lebih dari 50 tahun (66,7\% / 4 dari 6 orang), usia kehamilan anak pertama lebih dari 30 tahun $(10 \%)$.

Tabel 3: Nilai Pengetahuan Sadari Sebelum dan Sesudah Perlakuan

\begin{tabular}{lcc}
\hline \multicolumn{1}{c}{ Kriteria } & Nilai Pretest & Nilai Posttest \\
\hline Mean & 62,23 & 76,53 \\
Median & 63,00 & 81,50 \\
Mode & 60 & 87 \\
Range & 74 & 57 \\
Minimum & 13 & 43 \\
Maksimum & 87 & 100 \\
\hline
\end{tabular}

Tabel di atas menjelaskan bahwa nilai mean, nilai median, nilai minimum dan nilai maksimum pengetahuan setelah diberikan perlakuan lebih tinggi dari sebelum perlakuan.

Tabel 4: Distribusi Perbedaan Pengetahuan Sebelum dan Sesudah Perlakuan Hasil Uji Wilcoxon Signed Ranks Test

\begin{tabular}{llccc}
\hline \multicolumn{1}{c}{ Pengetahuan } & $\mathrm{n}$ & $\begin{array}{c}\text { Mean } \\
\text { Rank }\end{array}$ & $\begin{array}{c}\text { Sum of } \\
\text { Ranks }\end{array}$ \\
\hline Posttest & Negative Ranks & 3 & 7,17 & 21,50 \\
\cline { 2 - 5 } Pretest & Positive Ranks & 22 & 13,80 & 303,50 \\
\cline { 2 - 5 } & Ties & 5 & & \\
\cline { 2 - 5 } & Total & 30 & & \\
\hline p-value & 0,000 & & & \\
\hline
\end{tabular}

Tabel di atas menggambarkan bahwa ada perbedaan pengetahuan sebelum dan sesudah perlakuan $(p=0,000)$ dengan nilai positif ranks sebanyak 22 orang, dan negative ranks sebanyak 3 orang.

\section{PEMBAHASAN}

Sadari merupakan langkah awal yang sangat penting untuk mengetahui secara dini adanya tumor atau benjolan pada payudara Nisman (2011). Hampir 85\% gangguan atau benjolan ditemukan oleh penderita sendiri (Menteri Kesehatan, 2015). Pelaksanaannya sangat sederhana, dapat dilakukan sendiri, tidak menyita banyak waktu, beresiko rendah (Motahare Pilevarjadeh, 2016). Metode termurah dan mudah untuk mendeteksi kanker payudara secara dini (Shalini, Divya Varghese, and Malathi Nayak, 2011).

Keuntungan dari deteksi dini adalah meningkatkan survival rate. Berdasarkan data yang didapatkan dari PERABOI pada Tahun 2003 dalam Menteri Kesehatan (2015), didapatkan data prognosis daya tahan hidup penderita Kanker Payudara (survival rate) per stadium sebagai berikut : Stadium 0 : 10-years survival ratenya 98\% (nonpalpable breast cancer yang terdeteksi oleh Mammografi/ USG) ; Stadium I : 5-years survival ratenya $85 \%$; Stadium II : 5-years survival ratenya 60$70 \%$; Stadium III : 5-years survival ratenya $30-50 \%$; Stadium IV : 5-years survival ratenya $15 \%$ Stadium I : 5-years survival ratenya $85 \%$.

Banyak keuntungan dari sadari, akan tetapi tidak banyak wanita yang melakukannya. Penelitian Shalini, Divya Varghese, and Malathi Nayak (2011) mengungkapkan hanya $8,5 \%$ dari pelajar India yang melakukan sadari dengan benar selama pendidikan. Sementara hasil penelitian ini mengungkapkan dari 30 keluarga penderita kanker payudara yang menjadi partisipan, tidak ada satupun (0\%) yang melakukan sadari rutin tiap bulan. Kemungkinan salah satu penyebab tidak melakukan sadari dikarenakan rendahnya pengetahuan. Penelitian Kelechi Elizabeth Oladimeji (2015), 425 orang relawan $(70,8 \%)$ tidak tahu bagaimana melakukan sadari. Azami-Aghdash S (2015) menyebutkan salah satu hambatan yang paling penting dari perilaku skrening kanker payudara adalah kurangnya pengetahuan.

Pengetahuan adalah hasil "tahu" dan ini terjadi setelah orang tersebut melakukan penginderaan terhadap objek tertentu (Notoadmojo, 2014). Nilai mean pretest pengetahuan tentang kanker payudara dan deteksi dini pada penelitian ini adalah 62,33. Melalui analisis lembar jawaban kuesioner penelitian ini, diketahui rendahnya nilai pretest dikarenakan tidak mudah untuk mendapatkan informasi tentang cara sadari. Setelah partisipan menonton video dengan pendekatan HBM 
didapatkan nilai mean postest 76,53 (meningkat sebesar 14,22). Hasil analisis bivariat didapat nilai Wilcoxon Signed Ranks Test ( $\mathrm{p}=0,000$; positif ranks 22) Dari nilai ini dapat disimpulkan bahwa ada perbedaan nilai pretest dan posttest, dimana nilai posttest lebih tinggi. Data menggambarkan ada 22 partisipan mengalami peningkatan nilai posttest .

Hasil penelitian di atas, menunjukkan bahwa media video yang dirancang dengan pendekatan HBM mampu menggerakkan partisipan untuk tetap menonton video hingga selesai. Dampak positif dari menonton video HBM tersebut adalah peningkatan nilai pengetahuan keluarga penderita kanker payudara. Peningkatan ini meliputi : 1) faktor resiko kanker payudara 2) manfaat sadari sebagai langkah awal untuk mengetahui secara dini adanya tumor / benjolan pada payudara 3) operasi kanker payudara stadium dini dengan ukuran tumor kecil tidak mengangkat seluruh payudara, tetapi hanya mengangkat tumor dan beberapa jaringan yang ada di sekitarnya (lumpektomi), 4) sadari tidak menyakitkan, tidak melanggar etika dan dilakukan sebulan sekali tanpa pertolongan orang lain, 5) kemungkinan kerugian yang didapat bila tidak melakukan sadari.

\section{KESIMPULAN}

Berdasarkan hasil penelitian dan pembahasan dapat ditarik kesimpulan bahwa pendekatan HBM dengan menggunakan media video dapat meningkatkan pengetahuan keluarga penderita kanker payudara.

Selanjutnya disarankan agar pendekatan HBM dengan media video diterapkan sebagai media pendidikan kesehatan dengan sasaran kelompok dan masyarakat.

\section{DAFTAR PUSTAKA}

American Cancer Society. (2015). Breast Cancer Facts \& Figures. Atlanta: American Cancer Society, Inc.

Aghdash, A., Ghojazadeh, M., Sheyklo S.G., Daemi, A., Kolahdouzan, K., Mohseni, M., \& Moosav, A. (2015). Breast Cancer Screening Barriers from the Womans Perspective: a Meta-synthesis Saber. Asian Pacific Journal of Cancer Prevention. Vol 16, 2015.

Oladimeji, K.E., dkk. (2015). Knowledge and Beliefs of Breast SelfExamination and Breast Cancer among Market Women in Ibadan, South West, Nigeria. Diakses dari https://www.ncbi.nlm.nih.gov/pmc/a rticles/PMC4659560.

Menteri Kesehatan. 2015. Peraturan Menteri Kesehatan Republik Indonesia (Permenkes RI) Nomor 34 Tahun $2015 \quad$ Tentang Penanggulangan Kanker Payudara Dan Kanker Leher Rahim. Jakarta: Kemenkes RI.

Kemenkes RI, (2015). Situasi Penyakit Kanker, Buletin Jendela Data dan Informasi Kesehatan, semester 1 2015. Jakarta: Pusat Data dan Informasi Kementerian Kesehatan.

Moodi, M. (2011). Evaluation Of Breast Self-Examination Program Using Health. Journal of Research in Medical Sciences March 2011; Vol 16, No 3.

Pilevarjadeh. M. (2016). Women's Perspective of Breast Selfexamination. Int J Biomed Sci, 115119.

Nisman, W. A. (2011). Lima Menit Kenali Payudara. Yogyakarta: Andi Offset.

Notoadmojo, S. (2014). Ilmu Perilaku Kesehatan. Jakarta : Rineka Cipta.

Rumah Sakit Dr.H.Abdoel Muluk. (2017). Rekam Medik. Bandar Lampung: RSUDAM.

Shalini, Varghese \& Nayak, M. (2011). Awareness and Impact of Education on Breast Self Examination Among College 
Going Girls. Indian J Palliat Care, 150-154.

Mostafa, S.S., Neamatzadeh, G.K, Hossein \& Kargar, S. (2014). Health Beliefs and Breast Cancer Screening Behaviors among Iranian Female Health Workers. Asian Pacific Journal of Cancer Prevention, Vol 15.

RamBihariLai, S.S., dkk. (2013). Self Breast Examinatiom : A Tool For Early Diagnosis Of Breast Cancer. American Journal of Public Health Research, 135-139.
Allan, S., McLeroy, K.R., \& Holtzman, D., (2010). Godfrey H. Hochbaum (1916-1999): From Social Psychology to Health Behavior and Health Education. American Journal of Public Health.

Susan, L. C., 2010, The Breast. Philadelphia: Saunders.

Akhtari, Z.M., Juni, M.H., Said, S.M., \& Ismail, I.Z. (2013). Beliefs and Behavior of Malaysia Undergraduate Female Students in a Public University Toward Breast Selfexamination Practice. Asian Pacific Journal Of Cancer Prevention. 